\title{
Cancer in Lebanon: A Review of Incidence Rates from 2008 to 2015 and Projections Till 2025
}

\author{
Hussein H. Khachfe ${ }^{1,2}$ Zahraa Rahal ${ }^{1} \quad$ Julie Sammouri ${ }^{1} \quad$ Mira Kheil $^{1} \quad$ Hussein Baydoun ${ }^{1}$ \\ Dana Chatila ${ }^{1}$ Hiba Dirawi ${ }^{1}$ Fouad M. Fouad ${ }^{3}$
}

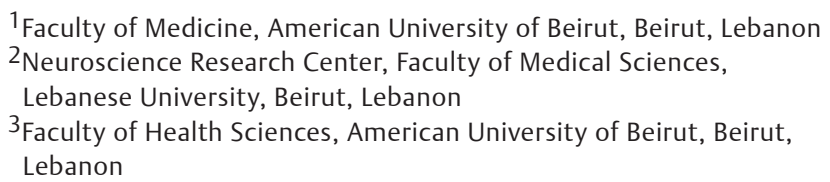

Address for correspondence Hussein H. Khachfe, Faculty of Medicine, American University of Beirut, Beirut, Lebanon (e-mail: hhk15@mail.aub.edu).

\section{South Asian J Cancer 2020;9:147-152.}

\begin{abstract}

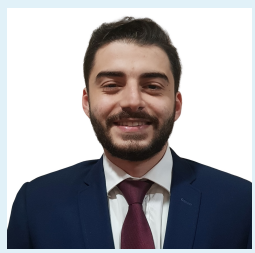

Dr Hussein H. Khachfe

Background and Objectives Cancer carries one of the heaviest burdens globally in terms of mortality. Lebanon is a middle-income Middle East country also plagued with cancer, as such a study and analysis of cancer trends and projections would serve a great benefit in the fight against the disease.

Materials and Methods All data pertaining to cancers in Lebanon were extracted from the National Cancer Registry of Lebanon Web site. Data were analyzed to produce trends over the years of our study (2008-2015). Ten-year projections were further calculated for the top cancers by the primary site using logarithmic models.

Results The top cancers in Lebanon are the breast, lung, colorectal, bladder, and

Keywords

- cancer

- epidemiology

- Lebanon

- Middle East

- neoplasia

- North Africa top cancers affecting males are the prostate, lung, and bladder. Cancer cases are projected to increase in Lebanon over the next 10 years.

Conclusion Lebanon had a steady incidence rate of cancer cases during the time of our study. A more complete understanding of cancer trends and their ultimate reduction will require further research into the origins of specific cancers and the means of prevention and control.
\end{abstract}

\section{Introduction}

Cancer is considered a heavy global burden nowadays. It is, in fact, the second leading cause of death worldwide following cardiovascular diseases. ${ }^{1,2}$ However, the trends seem to be different when comparing countries of uneven socioeconomic status. ${ }^{3}$ Developed countries such as those in Europe or the United States, for instance, are witnessing a decline in cancer incidence and mortality. In contrast, an increase in cancer incidence is seen in the poorer, less developed countries. ${ }^{4}$

Population-based cancer registries first appeared in Germany in 1929. ${ }^{5}$ Ever since their establishment, these cancer registries have constituted a valuable tool for governments

How to cite this article: Khachfe HH. Rahal Z. Sammouri J. Kheil M. Baydoun H. Chatila D. Dirawi H. Fouad FM. Cancer in Lebanon: A Review of Incidence Rates from 2008 to 2015 and Projections Till 2025. South Asian J Cancer 2020;9(3):147-152.

DOI https://doi.org/10.1055/s-0040-1721291 ISSN 2278-330X. allowing them to follow up and understand the cancer trend in their country. Initially, the role of the registries was confined to estimating cancer incidences and trends. However, the national cancer registries now serve several additional roles such as assessing risk factors and taking note of the family history as well as long-term survival. ${ }^{6}$ Registries also evaluate the efficacy of the existing screening systems and cancer control programs in an attempt to modify public health policies and improve the quality of patient care and health outcomes. ${ }^{5}$

Among the Arab countries, Lebanon has the highest incidence of cancer. ${ }^{7-9}$ Cancer imposes a problem for Lebanese citizens atop of the economic and political problems present

(C) 2020. MedIntel Services Pvt Ltd.

This is an open access articlepublished by Thieme under the terms of the Creative Commons Attribution-NonDerivative-NonCommercial-License, permitting copying and reproduction so long as the original work is given appropriate credit. Contents may not be used for commercial purposes, or adapted, remixed, transformed or built upon. (https://creativecommons.org/ licenses/by-nc-nd/4.0/)

Thieme Medical and Scientific Publishers Pvt. Ltd., A-12, 2nd Floor, Sector 2, Noida-201301 UP, India 
in the country. ${ }^{10-12}$ In 1998 , the Lebanese government established the "National Cancer Register." This recording system aims at measuring cancer incidence, classifying cases by age, sex, time, and place to establish a database to be used in further epidemiological studies. ${ }^{13,14}$

The latest study done to estimate cancer trends in Lebanon examined incidence and mortality between 2003 and 2008 while projecting data to 2018. ${ }^{10}$ Afterward, no other studies thoroughly examined the trends of the various cancers in Lebanon despite significant alterations in risk factors such as waterpipe smoking, obesity, excess alcohol intake, lack of physical activity, and environmental pollution. ${ }^{7}$

Therefore, an updated study on the incidence of cancer in Lebanon appears as essential. It will allow for more accurate projections given that they take into consideration current risk factors and trends. ${ }^{10}$

The aim of this study is to explore the direction of cancer trends in Lebanon during 2008 to 2015, provide insight on the future management of preventive and screening strategies, and generate projections of the obtained cancer incidence until the year 2025.

\section{Materials and Methods}

\section{Study Design}

This study was conducted in Lebanon, a middle-income country that represents developing countries in the Middle East and North Africa (MENA) region. Data were extracted from the National Cancer Registry (NCR) of Lebanon, which is part of the Ministry of Public Health epidemiological database. ${ }^{15}$ All data related to the primary site of cancer, age of patient, and gender were extracted. Data were compiled from 2008 to 2015 inclusive.

\section{Data Processing and Trend Analysis}

Sex-specific and incidence rates for each year of our study were calculated from 2008 to 2015. These rates were standardized to the World Standard Population to avoid any bias.

Annual percent change in the incidence rate of each cancer was analyzed using Joinpoint regression analysis.
The analysis was performed using Joinpoint 4.7.0.0. We assumed that statistical significance is at $p \leq 0.05$.

\section{Ten-Year Projected Estimates Until 2025}

We used our dataset and analysis from above to calculate predictions of different cancer incidence rates in Lebanon until 2025 (10 years). The incidence rates during the period of our study (2008-2015) were used in a logarithmic model, and years were extended toward 2025. We used a logarithmic model as it is the most biologically accurate model to describe cancer incidence. ${ }^{16}$ We used the $R^{2}$, which usually measures how accurately the model will explain the variations and check the $p$-value for the statistical significance of our model and results. We assumed values significant if $p \leq 0.05$.

\section{Results}

In the 8-year period of our study, a total of 88,285 new cases of cancer were indexed in the NCR of Lebanon. The number of indexed cancer cases increased from 9,308 to 13,013 during 2008 to 2015. Cancers were distributed according to a total of 58 different sites.

\section{Primary Site}

The top cancers that showed the most incidences in Lebanon are provided in -Table 1 . Among those breast and colorectal cancers were the ones with the top incidence rates being on average 44.84 cases per 100,000 and 23.25 cases per 100,000 , respectively. The site with the lowest incidence of cancer was thyroid and the stomach with 6.58 cases per 100,000 and 6.22 cases per 100,000 , respectively. Among the top cancers by primary site, prostate ( $p=0.001,95 \%$ confidence interval $[\mathrm{CI}])$, and bladder $(p=0.003,95 \% \mathrm{CI})$ cancers showed significant trends (decrease) throughout the years of our study.

\section{Age Group}

The age group that showed the most number of cancer cases was the 75 + years of age group with an average of 34.34 cases per 100,000 , followed by the age group of 70 to 74 years

Table 1 Top and total cancer incidence per 100,000 population according to primary site from 2008 to 2015 (inclusive) in both sexes and their annual percentage change

\begin{tabular}{|l|l|l|l|l|l|l|l|l|l|l|}
\hline Year & Breast & Lung & Colorectal & Prostate & Skin & Bladder & $\begin{array}{l}\text { Non-Hodgkin } \\
\text { lymphoma }\end{array}$ & Thyroid & Stomach & $\begin{array}{l}\text { All sites } \\
\text { (total) }\end{array}$ \\
\hline 2008 & 42.76 & 19.75 & 20.43 & 18.27 & 16.25 & 19.44 & 12.09 & 5.57 & 6.69 & 226.41 \\
\hline 2009 & 39.23 & 21.06 & 21.75 & 19.12 & 16.40 & 21.44 & 12.57 & 7.05 & 6.22 & 225.19 \\
\hline 2010 & 47.31 & 20.94 & 23.36 & 17.82 & 16.35 & 18.28 & 12.89 & 7.10 & 7.56 & 234.88 \\
\hline 2011 & 45.24 & 20.51 & 20.29 & 17.83 & 14.08 & 14.19 & 12.38 & 6.02 & 5.45 & 218.01 \\
\hline 2012 & 47.53 & 20.20 & 26.95 & 17.70 & 15.54 & 14.77 & 12.39 & 6.63 & 5.84 & 235.15 \\
\hline 2013 & 47.38 & 21.13 & 28.26 & 16.79 & 16.21 & 11.77 & 11.60 & 6.86 & 6.50 & 227.71 \\
\hline 2014 & 46.06 & 21.70 & 21.67 & 15.85 & 16.03 & 12.72 & 13.28 & 6.30 & 5.87 & 228.06 \\
\hline 2015 & 43.22 & 20.71 & 23.34 & 15.64 & 15.23 & 12.82 & 11.83 & 7.14 & 5.59 & 222.39 \\
\hline APC & 1.1 & 0.6 & 2.1 & $-2.6^{a}$ & -0.6 & $-7.8^{a}$ & -0.2 & 1.4 & -2.3 & -0.09 \\
\hline
\end{tabular}

Abbreviation: APC, annual percentage change.

${ }^{a} A P C$ is significantly different than zero. 
with 23.4 cases per 100,000 ( - Table 2 ). The age group with the lowest number of cases was the one of 0 to 4 years of age with only 1.04 cases per 100,000 throughout our study (-Table 2).

\section{Gender}

The cases of cancer were spread almost equally between males and females. They were 42,626 (48\%) and 45,451 (52\%), respectively. There was no statistical significance between males and females being affected by cancer $(p=0.36)$.

\section{Trends and Projections}

\section{Total Population}

Throughout our study (2008-2015), there is no significant change in the amount of new cancer cases per 100,000 . As for the 10-year projections we calculated, we expect that overall breast, colorectal, and lung cancers will have the highest incidence. For projections in 2025, our results expect a significant increase in breast $(p<0.001,95 \% \mathrm{CI})$, lung $(p=0.02,95 \%$ $\mathrm{CI})$, and colorectal cancers ( $p=0.01,95 \% \mathrm{CI}$ ), while we expect a significant decrease in prostate $(p<0.001,95 \% \mathrm{CI})$ and bladder $(p<0.01,95 \% \mathrm{CI})$ cancers ( - Table 3 ). Our analyses show a projection of around 20,000 new cases of cancer per year in Lebanon ( $>$ Fig. 1 ). The top three cancers predicted to be most present among the Lebanese population are the breast, lung, and colorectal (-Fig. 2).

Males

As for males, the incidence per 100,000 of prostate $(p=0.001$, $95 \% \mathrm{CI})$, bladder $(p=0.03,95 \% \mathrm{CI})$, and colorectal $(p=0.002$,

Table 2 Age-specific incidence rates (per 100,000) of cancer cases in Lebanon from 2008 to 2015 (inclusive)

\begin{tabular}{|c|c|c|c|c|c|c|c|c|c|c|c|c|c|c|c|c|}
\hline Years & $0-4$ & $5-9$ & $10-14$ & $15-19$ & $20-24$ & $25-29$ & $30-34$ & $35-39$ & $40-44$ & $45-49$ & $50-54$ & 55-59 & $60-64$ & $65-69$ & $70-74$ & $75+$ \\
\hline 2008 & 1.39 & 1.85 & 1.63 & 2.21 & 2.55 & 3.60 & 4.89 & 8.37 & 14.28 & 18.07 & 18.58 & 20.51 & 23.89 & 25.83 & 27.22 & 39.94 \\
\hline 2009 & 1.00 & 1.82 & 1.60 & 2.18 & 2.51 & 3.54 & 4.80 & 8.22 & 14.03 & 17.76 & 18.26 & 20.15 & 23.48 & 25.39 & 26.75 & 39.25 \\
\hline 2010 & 1.31 & 1.75 & 1.54 & 2.10 & 2.42 & 3.41 & 4.63 & 7.93 & 13.53 & 17.13 & 17.62 & 19.44 & 22.64 & 24.49 & 25.80 & 37.86 \\
\hline 2011 & 0.92 & 1.66 & 1.46 & 1.98 & 2.29 & 3.23 & 4.38 & 7.50 & 12.79 & 16.19 & 16.65 & 18.37 & 21.40 & 23.15 & 24.39 & 35.79 \\
\hline 2012 & 1.16 & 1.55 & 1.36 & 1.85 & 2.14 & 3.01 & 4.09 & 7.00 & 4 & 1 & .54 & 7.15 & 9.97 & 21.60 & 22.76 & 3.40 \\
\hline 2013 & 0.80 & 1.44 & 1.27 & 1.72 & 1.99 & 2.81 & 3.81 & 6.52 & 11.13 & 14.08 & 14.48 & 15.98 & 18.61 & 20.13 & 21.21 & 31.12 \\
\hline 2014 & 1.02 & 1.36 & 1.20 & 1.62 & 1.87 & 2.64 & 3.59 & 6.14 & 10.48 & 13.26 & 13.63 & 15.04 & 17.53 & 18.95 & 19.97 & 29.30 \\
\hline 2015 & 0.72 & 1.30 & 1.15 & 1.56 & 1.79 & 2.53 & 3.44 & 5.88 & 10.03 & 12.70 & 13.06 & 14.41 & 16.78 & 18.15 & 19.12 & 28.06 \\
\hline Average & 1.04 & 1.59 & 1.40 & 1.90 & 2.20 & 3.10 & 4.20 & 7.19 & 12.28 & 15.54 & 15.98 & 17.63 & 20.54 & 22.21 & 23.40 & 34.34 \\
\hline
\end{tabular}

Table 3 Ten-year projection of incidence per 100,000 population of top five cancers according to primary sites in both sexes and their annual percentage change

\begin{tabular}{|l|l|l|l|l|l|l|l|}
\hline Primary site & $\mathbf{2 0 1 5}(\mathbf{y})$ & $\mathbf{2 0 2 0}(\mathbf{y})$ & APC & Trend & $\mathbf{2 0 2 5}(\mathbf{y})$ & APC & Trend \\
\hline Breast & 43.22 & 48.49 & $2^{\mathrm{a}}$ & Rising & 50.88 & $1^{\mathrm{a}}$ & Rising $^{\mathrm{a}}$ \\
\hline Lung & 20.71 & 21.72 & $0.8^{\mathrm{a}}$ & Rising & 22.33 & $0.6^{\mathrm{a}}$ & Rising $^{\mathrm{a}}$ \\
\hline Prostate & 15.64 & 13.41 & $-3^{\mathrm{a}}$ & Declining & 11.15 & $-3.6^{\mathrm{a}}$ & Declining $^{\mathrm{a}}$ \\
\hline Bladder & 12.82 & 9.8 & $-4.7^{\mathrm{a}}$ & Declining & 8.4 & $-2.8^{\mathrm{a}}$ & Declining $^{\mathrm{a}}$ \\
\hline Colorectal & 23.34 & 26.42 & $2.4^{\mathrm{a}}$ & Rising $^{\mathrm{a}}$ & 28.92 & $1^{\mathrm{a}}$ & Rising $^{\mathrm{a}}$ \\
\hline
\end{tabular}

Abbreviation: APC, annual percentage change.

${ }^{a} A P C$ is significantly different than zero.

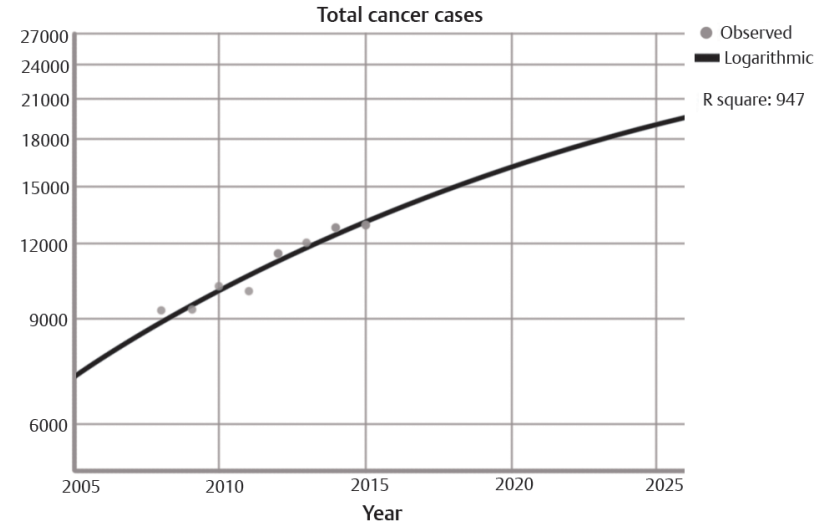

Fig. 1 Ten-year projection for total number of cancers in Lebanon till 2025.

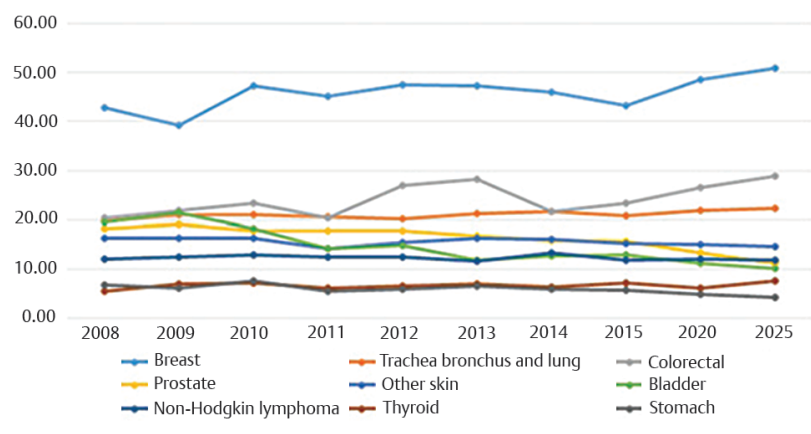

Fig. 2 Cancer trends and 10-year projections of incidence per 100,000 population by top cancer sites in Lebanon from 2008 to 2025. 
95\% CI) cancers are expected to significantly decrease, while lung cancer ( $p=0.01,95 \% \mathrm{CI})$ is expected to significantly increase ( - Table 4$)$.

\section{Females}

In females, we expect a significant increase in the incidence of breast ( $p=0.001,95 \% \mathrm{CI}$ ) and lung ( $p=0.003,95 \% \mathrm{CI}$ ) cancers and a significant decrease in the incidence of colorectal $(p=0.001,95 \% \mathrm{CI})$ cancer ( $\sim$ Table 5$)$.

\section{Discussion}

During the 8-year period (2008-2015) covered by the study, a cumulative increase in cancer incidence rates was observed. Based on our results, prostate, lung, and bladder malignancies remain the highest-reported cancers among males as described in a previous study assessing cancer trends by Shamseddine et $\mathrm{al}^{10}$ Similar to previous studies in Lebanon, breast cancer remains the highest reported malignancy in females, followed by lung and colon cancers. . $^{8,10,17,18}$ An increase in those cancers is expected to occur for both males and females by 2025, with increases in age being the most plausible explanation for the trends observed and the fact that most reported cases were from the 75+ age group.

In an effort to better elucidate the causes behind the observed trends of highest-reported cancer in males and females, each cancer will be explained individually.

\section{Prostate Cancer}

A direct correlation exists between prostate cancer and age. ${ }^{19}$ Almost $75 \%$ of new cancer cancers are diagnosed in the elderly. As such, the incidence of this malignancy is expected to increase with increases in life expectancy. In addition, increasing prostate cancer incidence appears to be related to better diagnosis. Previously, routine prostate-specific antigen (PSA) screening was done to all men from the age of 50 years. However, convincing evidence demonstrates that the PSA test often produces false-positive results $(\sim 80 \%) .{ }^{20}$ Accordingly, the most recent recommendation by the U. S. Preventive Services Task Force (USPSTF) advises against PSA-based screening for prostate cancer. ${ }^{21}$ Instead, physicians are urged to discuss with their patients the appropriateness of the test considering their clinical context. This recommendation stems from the fact that a substantial percentage of asymptomatic men diagnosed with prostate cancer following positive PSA results have a tumor that will progress slowly or will not progress at all, remaining asymptomatic in a man's lifetime..$^{22,23}$ As healthcare providers in Lebanon abide with the USPSTF recommendations, the increasing trend in prostate cancer incidence may slow down or even stabilize in the future, as demonstrated by the nonsignificant rising trend based on the 2025 projections.

\section{Lung Cancer}

Smoking, in all its forms, is correlated with escalating lung cancer epidemic. Statistics studying the prevalence of smoking in Lebanon has shown critical results as the percentage of adult-male smokers ranges between 50 and $60 \%,{ }^{24}$ whereas adult-female smokers bare the highest age-adjusted rates among female smokers within the MENA region. ${ }^{24,25}$ Furthermore, recent reports have shown that the per capita annual cigarette-smoking rate in Lebanon increased by an alarming $475 \%$ within the latest few decades. ${ }^{25,26}$ This increase comes as the second-largest increase in the number of smokers globally. ${ }^{26}$ Consequently, Lebanon was ranked the world's third in annual cigarette-smoking rate per capita for

Table 4 Ten-year prediction of incidence per 100,000 population of top five cancer sites among males and their annual percentage change

\begin{tabular}{|l|l|l|l|l|l|l|l|}
\hline Site & $2015(\mathbf{y})$ & $\mathbf{2 0 2 0}(\mathbf{y})$ & APC & Trend & $\mathbf{2 0 2 5}(\mathbf{y})$ & APC & Trend \\
\hline Prostate & 31.17 & 27.24 & $-3^{\mathrm{a}}$ & Declining & 22.90 & $-3.7^{\mathrm{a}}$ & Declining $^{\mathrm{a}}$ \\
\hline Lung & 27.79 & 28.74 & $1^{\mathrm{a}}$ & Rising & 29.31 & $0.6^{\mathrm{a}}$ & Rising $^{\mathrm{a}}$ \\
\hline Bladder & 20.92 & 15.22 & $-6^{\mathrm{a}}$ & Declining & 13.13 & $-2.9^{\mathrm{a}}$ & Declining $^{\mathrm{a}}$ \\
\hline Skin & 17.36 & 18.08 & 0.4 & Rising & 17.49 & 0.7 & Rising \\
\hline Colorectal & 20.23 & 16.25 & $-4.3^{\mathrm{a}}$ & Declining & 12.36 & $-5.3^{\mathrm{a}}$ & Declining $^{\mathrm{a}}$ \\
\hline
\end{tabular}

Abbreviation: APC, annual percentage change.

${ }^{\mathrm{a} A P C}$ is significantly different than zero.

Table 5 Ten-year predication of incidence per 100,000 population of top five cancer sites among females and their annual percentage change

\begin{tabular}{|l|l|l|l|l|l|l|l|}
\hline Site & $\mathbf{2 0 1 5}$ & $\mathbf{2 0 2 0}$ & APC & Trend & $\mathbf{2 0 2 5}$ & APC & Trend \\
\hline Breast & 84.52 & 95.07 & $2^{\text {a }}$ & Rising & 99.88 & $1^{\text {a }}$ & Rising $^{\text {a }}$ \\
\hline Lung & 13.63 & 13.90 & $0.4^{\text {a }}$ & Rising $^{\text {a }}$ & 14.23 & $0.5^{\text {a }}$ & Rising $^{\text {a }}$ \\
\hline Colorectal & 17.12 & 13.80 & $-4.3^{\text {a }}$ & Declining & 10.34 & $-5.6^{a}$ & Declining $^{\text {a }}$ \\
\hline Skin & 13.09 & 11.94 & $-1.5^{\text {a }}$ & Declining & 11.51 & -0.7 & Declining \\
\hline Non-Hodgkin lymphoma & 10.59 & 10.39 & -0.5 & Declining & 10.02 & -0.7 & Declining \\
\hline
\end{tabular}

Abbreviation: APC, annual percentage change.

${ }^{a} \mathrm{APC}$ is significantly different than zero. 
both genders combined. ${ }^{25,26}$ In relevance to both reports, the increase in smoking rates in Lebanon will definitely result in an upsurge in the rates of lung cancer patients. Besides cigarette smoking, tobacco products comprise many other fashioned alternatives among which is the waterpipe smoking, which goes by other names such as shisha, hookah, or "narghile." ${ }^{27}$ Waterpipe smoking is more culturally consented compared with cigarette smoking in Lebanon, and it is popularly common, although faultily, that the waterpipe is safer to smoke than cigarettes and that it can serve as among the nonaddictive alternatives to cigarettes. ${ }^{28-30}$ Hence, one can plausibly draw the correlation between the cultural accepting view toward waterpipes and the increase in health risks within the respective community, more specifically within teenagers and the younger generations within the community. Despite smoking being the primary causative factor behind smoking-induced lung cancer, a substantial number of people die of respiratory diseases attributed to air pollution. ${ }^{31}$ Indeed, air pollution can be considered as a significant risk factor for lung cancer in Lebanon. Notably, after the significant peak of air pollutants following the waste management crisis of 2015, a further increase in lung cancer incidence is to be expected..$^{32}$ Consequently, it cannot be emphasized enough how crucial is the strict implementation of tobacco control policies in Lebanon, along with developing strict environmental strategies to lessen the burden of air pollutants.

\section{Bladder Cancer}

In sharp contrast to worldwide trends, incidence rates and projections of bladder cancer in the 8-years period (2008-2015) covered by our study are exhibiting a declining trend. This contradicts the previous pattern reported by previous studies. ${ }^{10,23,33}$ Shamseddine et al reported increasing incidence rates of bladder cancer between 2003 and 2008 in the Lebanese population, with rates exceeding those of neighboring countries. ${ }^{10}$ Bladder cancer, similar to lung cancer, is smoking-related cancer. ${ }^{34}$ Consequently, incidence rates are expected to rise with increasing smoking prevalence and the poor implementation of tobacco control policies in Lebanon. As such, it is plausible to postulate that bladder cancer cases in Lebanon were not sufficiently captured in Lebanon by the NCR during the period covered by our study, leading to the observed trend. This further accentuates the need to improve the NCR, which will be discussed later in our study, to reflect more accurately the current cancer burden in the country.

\section{Breast Cancer}

Breast cancer continues to impose a substantial burden on the Lebanese population. Compared with Western countries, breast cancer presents in Lebanon in younger females. ${ }^{18,35}$ The rise in breast cancer incidence can be partly explained by earlier detection achieved thanks to the widespread national breast cancer awareness campaigns as well as fees reduction of mammography screening adopted within various nongovernmental organizations and healthcare centers. In addition, other factors may also contribute to the observed trend. For instance, the nutritional shift from a Mediterranean diet to a more Westernized one might be a possible explanation for the increase in cancer incidence. ${ }^{36}$ In addition, a decrease in fertility rates with more advanced age of marriage and fewer conceived children can further explain the observed rise in incidence. ${ }^{1,37}$

\section{Colorectal Cancer}

As many other cancers, the increase in colon cancer can be explained partly by the aging population. In addition, many other contributing factors can be identified. For instance, a sedentary lifestyle, an unhealthy eating diet (e.g., high intake of meat and fat versus low intake of fruits and vegetables), use of nonsteroidal anti-inflammatory drugs, smoking, obesity, and possibly hormonal factors can be considered as risk factors for the development of colon cancer. ${ }^{14}$ These factors have all been shown to be present among the Lebanese population, which has put people at a higher risk of developing malignancy. Furthermore, increased awareness concerning screening measures and organizing awareness campaigns for early detection of colorectal cancer may have contributed to the increase in incidence rates in Lebanon.

Increased research and more efforts put into the study of diseases in Lebanon, especially cancer is required to better improve both the NCR and prognosis of patients affected by the disease. ${ }^{38-40}$

\section{Conclusion}

Lebanon has witnessed an increase in cancer incidence rates among most tumors during the 2008 to 2015 . This increase can be explained partly by an aging population, and by early detection of cancer. However, many other risk factors (e.g. environmental, lifestyle) also come into play leading to the observed trends, albeit to lesser degree due to a short latency period. A more complete understanding of cancer trends and their ultimate reduction will require further research into the origins of specific cancers and the means of prevention and control. In addition, projected incidence rates signal further increase in the overall number of future cancer cases in the country. Consequently, public health interventions must be implemented, such as strict tobacco control policies, along with awareness campaigns activities.

The NCR of Lebanon is good but still needs proper reform to become ideal and optimal to be of further value in terms of research. Once centralization and coordination between public and private sectors occur along with the addition of factors such as mortality rates and staging, then adequate screening and prevention programs may stem from the NCR.

Funding

Nil.

Conflicts of Interest

There are no conflicts of interest.

Acknowledgments

The study protocol was approved by the Institutional

Review Board of the American University of Beirut. 


\section{References}

1 Fitzmaurice C, Allen C, Barber RM, et al. Global, regional, and national cancer incidence, mortality, years of life lost, years lived with disability, and disability-adjusted life-years for 32 cancer groups, 1990 to 2015: a systematic analysis for the global burden of disease study. JAMA Oncol 2017;3:524-548

2 Khachfe HH, Salhab HA, Fares MY, Khachfe HM. Current state of hypertrophic cardiomyopathy clinical trials. Glob Heart 2019;14(3):317-325

3 Clegg LX, Reichman ME, Miller BA, et al. Impact of socioeconomic status on cancer incidence and stage at diagnosis: selected findings from the surveillance, epidemiology, and end results: National Longitudinal Mortality Study. Cancer Causes Control 2009;20(4):417-435

4 Jemal A, Center MM, DeSantis C, Ward EM. Global patterns of cancer incidence and mortality rates and trends. Cancer Epidemiol Biomarkers Prev 2010;19(8):1893-1907

5 Bouchardy C, Rapiti E, Benhamou S. Cancer registries can provide evidence-based data to improve quality of care and prevent cancer deaths. Ecancermedicalscience 2014;8:413

6 Andersen MR, Storm HH; Eurocourse Work Package 2 Group. Cancer registration, public health and the reform of the European data protection framework: abandoning or improving European public health research? Eur J Cancer 2015;51(9):1028-1038

7 Charafeddine MA, Olson SH, Mukherji D, Temraz SN, Abou-Alfa GK, Shamseddine AI. Proportion of cancer in a Middle eastern country attributable to established risk factors. BMC Cancer 2017;17(1):337

8 Fares MY, Salhab HA, Khachfe HH, Khachfe HM. Breast cancer epidemiology among Lebanese women: an 11-year analysis. Medicina (Kaunas) 2019;55(8):E463

9 Salhab HA, Fares MY, Khachfe HH, Khachfe HM. Epidemiological study of lung cancer incidence in Lebanon. Medicina (Kaunas) 2019;55(6):E217

10 Shamseddine A, Saleh A, Charafeddine M, et al. Cancer trends in Lebanon: a review of incidence rates for the period of 2003-2008 and projections until 2018. Popul Health Metr 2014;12(1):4

11 Fares Y, Fares J. Neurosurgery in Lebanon: history, development, and future challenges. World Neurosurg 2017;99:524-532

12 Khachfe HH, Refaat MM. Bibliometric analysis of cardiovascular disease research activity in the Arab world. Int Cardiovasc Forum J 2018;15:25-28

13 Adib SM, Daniel J, Ministry of Public Health National Cancer Registry Cancer in Lebanon 2003 in National Cancer Registry. Beirut, Lebanon, Lebanese Ministry of Public Health; 2006

14 Khachfe HH, Salhab HA, Fares MY, Khachfe HM. Probing the colorectal cancer incidence in Lebanon: an 11-year epidemiological study. J Gastrointest Cancer 2019;E463

15 Ministry of Public Health, National Cancer Registry of Lebanon. Lebanese Ministry of Public Health. Beirut, Lebanon; 2018

16 Dyba T, Hakulinen T. Comparison of different approaches to incidence prediction based on simple interpolation techniques. Stat Med 2000;19(13):1741-1752

17 El Asmar M, Bechnak A, Fares J, et al. Knowledge, attitudes and practices regarding breast cancer amongst Lebanese females in Beirut. Asian Pac J Cancer Prev 2018;19(3):625-631

18 Lakkis NA, Adib SM, Osman MH, Musharafieh UM, Hamadeh GN. Breast cancer in Lebanon: incidence and comparison to regional and Western countries. Cancer Epidemiol 2010;34(3):221-225

19 Gupta S, Gupta A, Saini AK, Majumder K, Sinha K, Chahal A. Prostate cancer: How young is too young? Curr Urol 2017;9(4):212-215

20 Schröder FH, Hugosson J, Roobol MJ, et al; ERSPC Investigators. Screening and prostate-cancer mortality in a randomized European study. N Engl J Med 2009;360(13):1320-1328
21 Force UT. Final Recommendation Statement. Prostate Cancer: Screening; 2017

22 Wilt TJ, Brawer MK, Barry MJ, et al. The Prostate cancer Intervention Versus Observation Trial:VA/NCI/AHRQ Cooperative Studies Program \#407 (PIVOT): design and baseline results of a randomized controlled trial comparing radical prostatectomy to watchful waiting for men with clinically localized prostate cancer. Contemp Clin Trials 2009;30(1):81-87

23 Haddad FG, Kattan J, Kourie HR. El Rassy E, Assi T, Adib SM. Geriatric cancer trends in the Middle-East: findings from Lebanese cancer projections until 2025. J Geriatr Oncol 2018;9(2):120-123

24 Khattab A, Javaid A, Iraqi G, et al; BREATHE Study Group. Smoking habits in the Middle East and North Africa: results of the BREATHE study. Respir Med 2012;106(2, Suppl 2) :S16-S24

25 Rahal Z, El Nemr S, Sinjab A, Chami H, Tfayli A, Kadara H. Smoking and lung cancer: a geo-regional perspective. Front Oncol 2017;7:194

26 International Agency for Research on Cancer, World Cancer Report. International Agency for Research on Cancer, France; 2014

27 Chaouachi K. A critique of the WHO TobReg's "Advisory Note" report entitled: "Waterpipe tobacco smoking: health effects, research needs and recommended actions by regulators". J Negat Results Biomed 2006;5:17

28 Tamim H, Al-Sahab B, Akkary G, et al. Cigarette and nargileh smoking practices among school students in Beirut, Lebanon. Am J Health Behav 2007;31(1):56-63

29 Primack BA, Sidani J, Agarwal AA, Shadel WG, Donny EC, Eissenberg TE. Prevalence of and associations with waterpipe tobacco smoking among U.S. university students. Ann Behav Med 2008;36(1):81-86

30 Aljarrah K, Ababneh ZQ, Al-Delaimy WK. Perceptions of hookah smoking harmfulness: predictors and characteristics among current hookah users. Tob Induc Dis 2009;5(1):16

31 World Health Organization, Ambient Air Pollution: A Global Assessment of Exposure and Burden of Disease. World Health Organization, Geneva, Switzerland; 2016

32 Hilal N, Fadlallah R, Jamal D, El-Jardali F. Approaching the Waste Crisis in Lebanon: Consequences and Insights into Solutions, in Knowledge to Policy (K2P) Center. Beirut, Lebanon: American University of Beirut; 2015

33 Temraz S, Haibe Y, Charafeddine M, Saifi O, Mukherji D, Shamseddine A. The unveiling of a new risk factor associated with bladder cancer in Lebanon. BMC Urol 2019;19(1):16

34 Freedman ND, Silverman DT, Hollenbeck AR, Schatzkin A, Abnet CC. Association between smoking and risk of bladder cancer among men and women. JAMA 2011;306(7):737-745

35 Fraser GE, Shavlik D. Risk factors, lifetime risk, and age at onset of breast cancer. Ann Epidemiol 1997;7(6):375-382

36 Naja F, Hwalla N, Itani L, Baalbaki S, Sibai A, Nasreddine L. A novel Mediterranean diet index from Lebanon: comparison with Europe. Eur J Nutr 2015;54(8):1229-1243

37 Naufal Rizkallah H, Moneim AA. The drop in fertility in Lebanon. Population (Paris) 1997;pp:1224-1233

38 Fares MY, Salhab HA, Khachfe HH, Fares Y, Fares J, Sports Medicine in the Arab world. In: Handbook of Healthcare in the Arab World. Cham: Springer; 2019

39 Khachfe HH, Zayyoun FJ, Sharif-Askari E, Ramadan W, Hallal N, Khachfe HM. Effect of leishmaniasis on the performance of elementary school students a case study among Syrian refugees in some Bekaa (Lebanon) area schools. J Epidemiol Glob Health 2019;9(4):266-273

40 Khachfe HH, Sammouri J, Salhab HA, Fares MY, El-Najjar R. Maternal mortality and health in the Arab World: A 25-year epidemiological study. J Obstet Gynaecol Res 2019; 45(12):2369-2376 